\title{
A dimensão criadora no trabalho docente: subsídios para a formação de professores alfabetizadores
}

\author{
Marli Lúcia Tonatto Zibetti \\ Universidade Federal de Rondônia \\ Marilene Proença Rebello de Souza \\ Universidade de São Paulo
}

\section{Resumo}

Este artigo tem como objetivo evidenciar a dimensão criadora dos saberes docentes mobilizados por uma professora alfabetizadora, a partir da concepção de saberes docentes desenvolvida pela teoria histórico-cultural. A pesquisa realizou-se em escola pública, no estado de Rondônia, por meio de uma abordagem etnográfica. 0 trabalho traz para a análise duas cenas recortadas do cotidiano escolar para exemplificar como os saberes docentes são alterados e recriados no enfrentamento dos desafios impostos pela prática pedagógica. Os resultados permitem compreender que a prática docente no cotidiano não se caracteriza apenas como reprodução de modelos ou propostas utilizadas por outros profissionais. Ao contrário, no encontro de uma professora e uma turma de alunos há sempre certa originalidade que demanda a criação de formas específicas de intervenção para aquele grupo, nas condições do contexto. Acompanhar o trabalho da professora durante o período de pesquisa permitiu compreender que há inúmeras possibilidades de condução do trabalho pedagógico e as razões que motivam as escolhas dos professores e das professoras estão fundamentadas em saberes construídos ao longo de suas experiências de formação e atuação. Considera-se, portanto, que as práticas pedagógicas precisam ser conhecidas e estudadas para que se possa compreendê-las, mais do que avaliá-las, tendo-se em vista a contribuição desses estudos para a formação docente.

\section{Palavras-chave}

Alfabetização - Saberes docentes - Formação de professores Pesquisa etnográfica.

\footnotetext{
Correspondência:

Marli Lúcia Tonatto Zibetti

Universidade Federal de Rondônia

Campus Rolim de Moura

Rua Jamari, 6616

78987-000 - Rolim de Moura - RO

E-mail: marlizibetti@yahoo.com.br
} 


\title{
The creative dimension of the teaching activity: elements for the formation of literacy teachers
}

\author{
Marli Lúcia Tonatto Zibetti \\ Universidade Federal de Rondônia \\ Marilene Proença Rebello de Souza \\ Universidade de São Paulo
}

\begin{abstract}
This article aims to bring forward the creative dimension of the teaching knowledges mobilized by a literacy teacher, and is based on the concept of teaching knowledges as developed in the culturalhistorical theory. The study was conducted in a public school of the State of Rondonia under an ethnographic approach. The work analyzes two episodes extracted from the school everyday life in order to exemplify how the teaching knowledges are changed and re-created when facing the challenges presented by the pedagogical practice. The results help to understand that the day-to-day teaching practice cannot be described simply as the reproduction of models or proposals used by other professionals. On the contrary, when teacher and class meet there is always an element of originality that demands the creation of forms of intervention specific for that group, under the conditions of that context. Following the work of the teacher during the period of the research made it possible to understand that there are countless possibilities of conduction of the pedagogical work, and that the reasons behind the teachers' choices are grounded in knowledges constructed throughout their experiences of formation and professional activity. It is concluded, therefore, that the pedagogical practices must be known and studied in order to be understood, more than judged, having in mind the contribution of these studies to teacher education.
\end{abstract}

\section{Keywords}

Literacy - Teaching knowledges - Teacher education Ethnographic research.

\footnotetext{
Contact:

Marli Lúcia Tonatto Zibetti

Universidade Federal de Rondônia

Campus Rolim de Moura

Rua Jamari, 6616

78987-000-Rolim de Moura - RO

E-mail:marlizibetti@yahoo.com.br
} 
A complexidade que envolve o campo da formação docente tem estimulado uma grande produção de estudos e pesquisas nessa área, bem como a diversificação das abordagens buscando encontrar alternativas para as críticas sofridas pelos professores em relação à qualidade da educação brasileira.

Inserem-se nesse cenário as pesquisas sobre a temática dos saberes docentes, as quais procuram compreender a constituição e a relação destes com os cursos de formação, buscando gerar novas contribuições aos processos formativos. Nos últimos vinte anos ampliaram-se as produções sobre o tema a partir de concepções e orientações variadas (Gauthier et. al., 1998; Borges, 2001, 2002; Tardif, 2002; Pimenta, 2002). Os diferentes enfoques sobre os saberes docentes valorizam a formação teórica e pedagógica para a constituição desses saberes e enfatizam o caráter formador e coletivo da experiência prática dos professores. Também buscam a construção de tipologias que permitem classificar os saberes de acordo com sua caracterização e constituição.

Nossa abordagem insere-se na perspectiva dos estudos do cotidiano (Heller, 1987; 1989) e inspira-se nos trabalhos de Rockwell e Mercado (1986), Rockwell (1990) e Mercado (1991; 2002). Neste enfoque, a apropriação dos saberes por parte dos docentes é resultado de um processo histórico no qual os professores transformam os conhecimentos a que tiveram acesso ao longo de sua formação e atuação profissional em saberes que são mobilizados no exercício da profissão. Portanto, úteis ou não à prática, mantidos ou modificados a partir de sua contribuição ao cumprimento das tarefas educativas.

Como atividade cotidiana, a prática docente em sala de aula carrega um forte componente de reprodução, característica básica da vida cotidiana, pois, como esclarece Heller (1989), “[...] na cotidianidade, não é possível concentrar todas as energias em cada decisão" (p. 25, grifos da autora). Por isso, muitas ações caracterizam-se como rotineiras e vão sendo reproduzidas, para tornar viável a sobrevi- vência e a atuação cotidianas. Determinados encaminhamentos do trabalho em sala, depois de apropriados pelos envolvidos, repetem-se diariamente e garantem que alguns aspectos da rotina de funcionamento da aula e da escola, da organização da turma enquanto grupo, da utilização de determinados materiais e espaços não precisem ser pensados todos os dias.

Entretanto, o trabalho docente não se caracteriza apenas como reprodução, pois mesmo que estejam presentes nas práticas pedagógicas saberes constituídos em outras épocas da docência, as professoras e os professores modificam, atualizam, alteram e criam novas formas de atuação, uma vez que

[...] a dialética entre objetivação e apropriação na história social implica também e necessariamente a dialética entre a reprodução do existente e a produção do novo, do ainda não existente. (Duarte, 2000, p. 121)

Durante o exercício da docência, professores e professoras deparam-se com momentos em que os saberes acumulados ao longo da profissão não são suficientes para atender às demandas trazidas por uma situação distinta, seja ela decorrência do encontro com um novo grupo de alunos(as), com crianças que não aprendem no mesmo ritmo que a maior parte da turma, com novas propostas de ensino, com a limitação de recursos etc. Nesses momentos, os(as) docentes são desafiados(as) a criar alternativas para levar adiante sua tarefa, encontrando diferentes formas de fazê-lo no contexto em que estão inseridos(as). Mesmo inspiradas em experiências anteriores, algumas dessas ações apresentam componentes novos e aparecem como resultado de um esforço de reflexão, ajuste e recombinação de saberes para dar conta ou, pelo menos, buscar soluções para os desafios surgidos na prática docente. É nesse contexto que o trabalho docente pode ser caracterizado como atividade criadora, pois a prática pedagógica emerge como espaço em que são gerados novos saberes. 
A partir das contribuições de Vigostsky (2003) sobre o conceito de atividade criadora, este trabalho objetiva evidenciar a dimensão criadora dos saberes docentes mobilizados por uma professora alfabetizadora, conforme dados obtidos em pesquisa etnográfica desenvolvida em uma escola pública no estado de Rondônia. Trazemos para a análise duas cenas recortadas do cotidiano escolar para exemplificar como os saberes docentes são alterados e recriados no enfrentamento dos desafios impostos pela prática pedagógica.

\section{Trabalho docente e atividade criadora}

Para Vigotsky (2003) pode-se denominar atividade criadora

[...] toda a atividade humana que não se limite a reproduzir fatos ou impressões vividas, senão que cria novas imagens, novas ações... (p. 9)

Ao trazer para a análise do trabalho docente o conceito de atividade criadora, pretendemos evidenciar que há um espaço na prática pedagógica cotidiana em que não é possível atuar apenas com base em saberes apropriados, em experiências vividas, ou em modelos consolidados, ou seja, por meio de uma práxis reiterativa, pois como explicam Rockwell e Mercado (1986), quando se trata de decidir o que ensinar e como fazê-lo, a atuação demanda a integração ou criação de novos conhecimentos:

Dado o processo de construção ativa do saber que requer o trabalho, se pode supor que a prática docente não é reprodução passiva da formação profissional ou das normas oficiais. A diversidade de práticas concretas nas escolas, a heterogeneidade de soluções aos problemas da instituição e a variedade de formas de ensinar demonstram que o processo de construção do saber do magistério é seletivo e inclusive inovador. (p. 69, grifo nosso)

Embora em vários momentos do trabalho pedagógico a utilização de saberes anterior- mente construídos seja necessária à própria atividade cotidiana, há situações nas quais esses saberes se revelam insuficientes e desafiam os profissionais a encontrar outras alternativas. E como afirma Vigotsky (2003), o fator determinante para o surgimento da atividade criadora é a necessidade:

[...] na base de toda ação criadora reside sempre uma inadaptação, fonte de necessidades, anseios e desejos. (p. 35-36)

Zorzal e Basso (2002) defendem a identificação entre a atividade transformadora do homem subentendida na atividade propriamente humana denominada trabalho e a faculdade que tem sido denominada eufemisticamente de criatividade. Para os autores, o gênero humano possui um caráter ontologicamente criativo e este é fundamental para que se possa entender a manifestação da criatividade em termos individuais.

A natureza histórico-cultural do gênero humano (produtor e transformador intencional de si mesmo através de seus bens e conhecimentos socialmente plasmados) é, necessária e ineliminavelmente, criadora. Assim sendo, toda e qualquer atividade humana que transforme intencionalmente materiais de qualquer natureza, é, necessária e essencialmente, criatividade. (p. 9, grifos dos autores)

Para explicitar o que entende por processos criativos, Vigotsky (2003) distingue dois tipos básicos de "impulsos": o primeiro, chamado de reprodutor ou reprodutivo, está relacionado à memória e tem por principal característica a reprodução de informações, impressões ou normas de condutas criadas e elaboradas. Nesses casos, não ocorre a criação de algo novo, pois a atividade limita-se a repetir algo previamente existente.

Embora a atividade reprodutora seja imprescindível na vida cotidiana, se o homem se limitasse à reprodução e conservação de experiências não seria capaz de atuar em função das necessidades e mudanças que ocorrem em 
seu meio. Para isso, torna-se imprescindível o segundo tipo de atividade do cérebro humano denominada por Vigotsky (2003) de atividade criadora ou combinadora. É graças a essa atividade que os seres humanos não estão limitados a reproduzir fatos e impressões vividas, mas são capazes de criar e reelaborar imagens e ações com vistas ao futuro:

\section{[...] é precisamente a atividade criadora do} homem que faz com que ele seja um ser projetado para o futuro, um ser que contribui para criar e modificar seu presente. (p. 9)

Costuma-se pensar que a criação é privilégio de algumas pessoas geniais ou talentosas e reconhece-se facilmente essa capacidade nos grandes inventores. Para o autor, essa concepção é injusta, pois existe criação não só nas grandes descobertas históricas, mas, também,

[...] onde o ser humano imagina, combina, modifica e cria algo novo, por insignificante que esta novidade pareça ao comparar-se com as realizações dos grandes gênios. (p. 11)

E, nesse sentido, só estaria distribuída desigualmente entre os seres humanos em decorrência das condições materiais, também desiguais, a que estão submetidos na sociedade.

Ainda segundo Vigotsky (2003), para criar o ser humano depende da experiência, das necessidades e de seus interesses. Além disso, depende também dos "conhecimentos técnicos, das tradições, ou seja, dos modelos de criação que influenciam o ser humano" (p. 36). Por isso, o autor afirma que todo inventor, por mais genial que seja, é sempre produto de sua época e de seu ambiente:

Nenhum descobrimento nem invenção científica aparece antes que se criem as condições materiais e psicológicas necessárias para seu surgimento. A obra criadora constitui um processo histórico consecutivo no qual cada nova forma se apoia nas precedentes. (p. 37-38)
Isso explicaria a porcentagem bem maior de criações científıcas, técnicas e artísticas entre as classes privilegiadas, uma vez que são essas classes que detêm em suas mãos todas as condições para criar.

A matéria-prima da imaginação criativa, afirma Vigotsky (2003) é encontrada na realidade das experiências do ser humano, pois, o "fantástico" é uma recombinação de elementos da realidade. Com base na riqueza e na variedade da experiência acumulada por homens e mulheres é que a atividade criadora se constitui e esta é a principal lei a que se subordina a função imaginativa. Portanto, embora a necessidade e o desejo sejam impulsionadores da criação, eles nada criam por si, sendo imprescindíveis que existam as condições materiais e psicológicas para tornar possível o surgimento de qualquer invenção.

Pelo próprio caráter essencialmente transformador e criador da atividade humana defendido por Vigotsky (2003), pode-se considerar o trabalho do professor como atividade humana que não pode ser desenvolvida apenas como reprodução, uma vez que implica a criação de novas formas de atuação tendo em vista as condições objetivas enfrentadas no cotidiano da prática pedagógica.

Ao se encontrar diante de um grupo de alunos com necessidades específicas, em determinadas condições de trabalho, cada professor e cada professora precisa lançar mão de suas experiências, de seus conhecimentos teóricos, dos recursos materiais de que dispõem para criar novas formas de intervenção pedagógica. Algumas vezes essas formas são fruto da recombinação de instrumentos e recursos conhecidos que passam a ser utilizados de forma diferenciada em outras circunstâncias. Porém, há situações em que são necessárias construções ainda não utilizadas e, a partir de sua concepção, são experimentadas e avaliadas tendo em vista os resultados obtidos.

Conforme explicitado por Vigotsky (2003), essa criação não ocorre no vazio e, portanto, é dependente das condições objetivas 
em que nos encontramos. No caso do trabalho docente, as condições materiais em que atua e também as oportunidades de acesso aos conhecimentos sobre o trabalho pedagógico, às ciências da educação e também às experiências de outros educadores e educadoras são elementos fundamentais para o processo de construção de novas formas de atuação por parte de professores e professoras.

\section{A dimensão criadora dos saberes docentes no cotidiano da alfabetização}

Os dados analisados neste artigo são oriundos de pesquisa etnográfica e foram produzidos por meio de observação participante, entrevistas e análise documental. A referida pesquisa foi realizada com uma professora que estava cursando Pedagogia em programa especial da Universidade Federal de Rondônia. Ela possuía experiência de mais de vinte anos na profissão e havia cursado magistério no Nível Médio. Atuava em uma escola pública estadual de Rondônia, com turmas de Ciclo Básico de alfabetização.

Para realizar o trabalho de alfabetização junto a alunos que vêm de diferentes experiências na Educação Infantil ou que nunca frequentaram a escola, as professoras alfabetizadoras precisam, entre outras atribuições, auxiliar as crianças a se apropriarem das regras que dirigem a convivência de um grupo no ambiente escolar e os combinados envolvidos na condução do trabalho em sala de aula, além de construírem com elas a dinâmica que imprimirão na abordagem dos conteúdos.

Conforme apontado por Talavera (1994), Mercado (1991) e também constatado em nossa pesquisa, o trabalho pedagógico, pelas condições objetivas em que é desenvolvido, apresenta características bastante desafiadoras. Uma única professora, responsável por um grupo de alunos precisa levar em conta as características de cada criança, o tempo e o espaço disponível, além do conteúdo a ser ensinado em determinada série. Para desenvolver tal trabalho, a professora terá que envolver as crianças naquilo que deseja que elas façam. Ou seja,

[...] o professor terá que fazer com que as crianças realizem uma série de atividades que elas não estão necessariamente interessadas em fazer. (Mercado, 1991, p. 65)

Para isso, as tarefas não podem ser impostas de forma coercitiva, mas os mestres precisam trabalhar no sentido de obter o envolvimento real das crianças, desafio a ser enfrentado tanto durante a atuação quanto no planejamento, conforme evidenciam as análises a seguir.

\section{A dimensão criadora dos saberes e os desafios da condução da aula}

A Cena 01, apresentada a seguir, exemplifica uma situação ocorrida em sala de aula em que a professora deparou-se com o desafio de envolver o grupo todo em uma atividade em que as crianças precisavam falar e ouvir umas às outras sob a coordenação da professora. As dificuldades enfrentadas na condução da atividade obrigam a professora a lançar mão de uma estratégia que ainda não havia utilizado em outra circunstância: a organização das crianças em uma roda, para que pudesse obter a atenção de todos durante a conversa.

Continuou o diálogo pedindo que as crianças contassem algumas coisas que haviam conversado com as mães, conforme ela havia solicitado na semana passada. Carlos tenta contar que sua mãe não tinha tempo de brincar porque precisava ir buscar água. A professora repete o que ele disse para o grupo, pois há muitas conversas paralelas e as crianças não ouvem o que o colega fala.

A professora chama atenção dos alunos: "Vamos ouvir o colega contar sobre a história de sua mãe. Quem mais gostaria de contar alguma coisa?".

As crianças estão agitadas e poucas ouvem o que está sendo dito. Próximo ao local em que 
estou sentada Rivaldo e José empurram-se, cutucam-se e a professora precisa chamar a atenção. Basta chamá-los pelo nome: "Rivaldo e José, por favor!".

Mas quando estes se acalmam já há outros dois conversando alto ou empurrando-se ou levantando para provocar um outro colega que está mais distante. A professora pacientemente leva alguns para sentar, pede que outros ouçam e procura continuar conversando com eles. "O que vocês gostariam de saber sobre a história de vida desta mãe que vem aqui?".

Lucas Alberto com uma expressão de riso no rosto responde: "Eu queria saber como a gente nasce". E olha para os lados, esperando a reação dos colegas. As crianças continuam conversando entre si e não manifestam reações. A professora então vem em direção ao aluno e diz para ele: "A professora vai preparar uma aula sobre o assunto e vou explicar direitinho para vocês como nós nascemos". E já mais próxima diz a ele: "Mas você pode pedir também para sua mãe te explicar o que você quer saber". E ele responde: "Minha mãe não explica nada, professora!”.

A professora volta para frente da sala e tenta chamar a atenção das crianças sobre o tema a ser discutido. Kevin a interrompe e diz: "Não pode pedir essas coisas para a mãe, não é professora? É feio!" referindo-se à pergunta de Lucas. A professora diz que eles estão fugindo do assunto e pergunta se eles não querem conversar com a mãe sobre a história dela, onde ela nasceu, de onde ela veio, por exemplo, se ela brincava quando era criança e de quê etc. Lucia afırma: "Eu não quero perguntar nada sobre as mães. Isso é muito chato!”.

A professora não responde e continua tentando ouvir as crianças que querem falar. Como o diálogo estava difícil porque as crianças falavam ao mesmo tempo a professora pergunta: "Vocês querem ir para a sala de vídeo para a gente sentar na roda e poder continuar conversando?". As crianças em coro respondem "Sim!".
Roberto comenta: "Vamo faze uma roda como no Clone e cada um entra pra fala um pouco". Outra criança diz: "Eu vi no Clone eles falando sobre droga!".

Jéferson completa: "Nós vamo faze a roda só que é pra fala da família da gente!".

A professora chama a atenção das crianças para a opinião do colega: "Olha o que o Jéferson está dizendo: que nossa roda é igual à do Clone só que nós vamos falar sobre a família”.

Ela então pede que eles não corram e que lá deverão lembrar das regras da sala, ouvindo os colegas falar. Explica ainda que aquele que correr vai voltar. Lucas diz que não vai ficar quieto. A professora, sem alterar a voz afirma "Se você não respeitar as regras da nossa sala, você vai ficar na Direção até a gente voltar. E se precisar nós vamos chamar a mãe para conversar com a gente".

Lucas: "Não, professora! Não chama minha mãe, não!”.

A professora fala: "Então vamos!".

As crianças levantam-se e vão saindo em direção à sala de vídeo acompanhadas por mim e pela professora. Ao chegarmos à sala, a professora pede que todos se sentem no tapete, em círculo, de maneira que possamos ficar uns de frente para os outros.

Algumas crianças sentam-se imediatamente nos tapetes e aguardam a professora. Outras ficam andando pela sala, pegam revistas, livros ou algum jogo de montar e a professora precisa recolher um por um e pedir que as crianças sentem na roda. Assim que ela consegue organizá-los, (o que demora alguns minutos) senta-se também e Nilson acomoda-se à sua frente, quase se sentando em seu colo.

A professora pede quem quer ir para o centro da roda para falar. Bianca se oferece e entra na roda. A professora pede o que ela tem para contar. Como ela fica tímida a professora começa a perguntar:

1. Trata-se de uma novela veiculada pela Rede Globo de Televisão e, pelo que se pode perceber, assistida pelas crianças que fizeram menção a um grupo de autoajuda que participava dessa novela. 
Profa: Você sabe quantos anos sua mãe tem? Bianca: 26.

Profa: Você pediu para ela do que ela brincava quando era criança?

Bianca: Ela disse que fazia casinha com pedaços de madeira como se fosse casinha de verdade. [...]

Outras crianças entraram na roda e falaram um pouco sobre o que haviam conversado com as mães. A professora perguntava se eles conheciam as avós, se sabiam onde a mãe havia nascido, o que a mãe mais gostava.

Kevin, Roberto, Carlos, Lucia e Inês também falam sobre suas mães. Lucia conta que a mãe fazia bonecas de pedaços de madeira e a professora conta que ela também, apesar de ter muitas bonecas, fazia outras com sabugo de milho que ela envolvia com toucas e colocava para dormir em latas de sardinha vazias que se transformavam em berços.

Com Inês o diálogo foi diferente, pois a professora sabe que ela perdeu os pais e mora com uma tia. Perguntou para ela se ela lembrava de alguma coisa que a mãe fazia. Inês falava muito baixo e eu não consegui ouvir sua resposta. A professora perguntou ainda se ela lembrava como a mãe a tratava. Ela disse que a mãe era muito carinhosa. [...]

A professora pergunta se mais alguém quer falar, contar alguma coisa do que conversou com sua mãe. Nenhum aluno se manifesta e então ela pede que voltem para a sala. Algumas crianças aproveitam pra tomar água e ir ao banheiro. Voltamos para a sala conversando e eu destaquei algumas crianças que percebi muito atentas ao que os demais falavam. A professora disse que deveria ter trabalhado antes com este grupo atividades como estas em que precisam falar e saber ouvir. Disse: "A gente está estudando que é preciso tirar deles as informações, mas às vezes eu ainda não sei como fazer isso". (Observação, 17 jun. 2002)

A complexidade do trabalho com crianças pequenas torna-se bastante evidente na situação descrita na Cena 01, na qual foi possível observar a professora enfrentando o desafio de coordenar uma conversa com a turma, orientada pelo objetivo de trazer as experiências das crianças para o contexto do trabalho pedagógico. Porém, entre o objetivo planejado e a realização da atividade há um percurso que precisa ser trilhado pelos(as) professores(as) no cotidiano do trabalho docente. Algumas vezes esse percurso pode ser antecipado e, portanto, os instrumentos necessários para realizá-lo com êxito podem ser construídos com antecedência. Em outras circunstâncias, os(as) professores(as) precisam lançar mão dos saberes disponíveis, mobilizando-os em favor dos objetivos traçados e modificando-os nas circunstâncias de atuação. Como destaca Mercado (2002),

[...] há uma tensão e um interjogo entre a preparação prévia dos professores e as improvisações às quais recorrem diante das demandas e reações dos alunos. (p. 95)

Improvisação entendida com base nas afirmações de Erickson (1982) como decorrência da interação social.

$\mathrm{Na}$ Cena 01 a professora busca diferentes formas de envolvimento das crianças com a tarefa. Inicia explicitando o objetivo da atividade, ao mesmo tempo que lança um questionamento visando dar continuidade ao diálogo: "vamos ouvir o colega contar sobre a história de sua mãe. Quem mais gostaria de contar alguma coisa?”.

Quando Lucas procura, intencionalmente, desviar o rumo da conversa, a professora acolhe seu questionamento, porém, chama-o de volta para a tarefa explicitando que o assunto não estava sendo discutido naquele momento, mas poderia ser abordado em outra ocasião. Assim, conforme nos explica Mercado (1991, p. 66) o professor age com um saber docente relativo às formas específicas de tratar as crianças:

Diante de suas exigências, que não se relacionam com aquilo que ele [professor] procura fazer na atividade, não os censura, legitimando desta maneira, a livre expressão, ainda que não responda nos termos que as crianças lhe solicitam. 
As intervenções ocasionais dos alunos e alunas durante a aula caracterizam-se como situações dilemáticas na atuação cotidiana. Ou seja, a professora precisava decidir naquele momento como agir em relação à solicitação do aluno. Se ela passasse a discutir a temática proposta por Lucas, sua aula tomaria outro rumo. Por outro lado, adiar a discussão do assunto nem sempre é a melhor decisão, pois pode causar desinteresse por parte do grupo. No caso específico da Cena analisada e, considerando que a docente muitas vezes atendeu às solicitações dos(as) alunos(as) e alterou o andamento da aula, duas questões podem ter contribuído para que ela não o fizesse nesse caso. A primeira diz respeito ao tema, muitas vezes considerado delicado para abordagem pelos professores sem uma preparação prévia. E a segunda, pelo fato dos(as) demais alunos(as) não terem se manifestado em favor da solicitação de Lucas, que explicitamente a fez com um propósito provocador.

Na intervenção de Lúcia em que explicitou sua recusa em participar, a professora silencia, mas seu silêncio informa que não interromperá a atividade enquanto houver alunos interessados em falar sobre o assunto. Mas as dificuldades em fazê-los(as) ouvir parecem exigir da professora a superação das alternativas experimentadas e ela, então, propõem que se desloquem para um espaço que, algumas vezes, fora utilizado para a realização de atividades de leitura: a sala de vídeo (que também serve de biblioteca).

Conforme esclarece Vigotsky (2003),

[...] a atividade criadora da imaginação se encontra em relação direta com a riqueza e a variedade da experiência acumulada pelo homem... (p. 17)

A professora, naquele momento, utilizou dados de sua experiência na docência, recombinando-os em um novo encaminhamento, pois o procedimento utilizado anteriormente como "Roda de Leitura" passou, a partir daquele momento, a servir também para a realização de "Rodas de
Conversa”. Rapidamente as crianças relacionam a roda de conversa à experiência dos grupos de autoajuda que haviam assistido na televisão durante a novela $O$ clone e a professora aproveita a afırmação de Jéferson para socializar, com a sala toda, o sentido atribuído por algumas crianças à proposta feita por ela: “olha o que o Jéferson está dizendo: que nossa roda é igual à do Clone só que nós vamos falar sobre a família".

No momento em que se preparavam para mudar de ambiente, a professora retoma os combinados que devem guiar o comportamento da turma e precisa deixar claro seu papel de gestora da classe quando Lucas desafia as regras estabelecidas. Gauthier et al. (1998) afirmam, com base na análise de pesquisas realizadas em sala de aula, que

\section{[...] os professores mais bem-sucedidos no} que diz respeito à gestão da classe planejam e chamam a atenção dos alunos para as consequências decorrentes da violação das regras já explicitadas. (p. 243)

Uma situação como essa requer, por parte dos(as) professores(as), a mobilização de uma série de saberes que lhes permitam atuar, ao mesmo tempo, com a sala toda e com cada um(a) dos(as) alunos(as), constituindo-se como uma das principais preocupações dos(as) docentes.

0 diálogo conduzido pela professora com cada um dos alunos possibilita que observemos a adequação da intervenção às necessidades das crianças. Quando Bianca se dispõe a entrar na roda, tem a intenção de compartilhar com os(as) colegas aquilo que ouviu de sua mãe, mas ao fazê-lo sente-se intimidada e a professora vem em seu auxílio com perguntas que garantem à aluna sua participação na atividade. Com Inês, o diálogo assume outra direção e revela que a professora atua com base em um amplo conjunto de informações sobre as crianças e sobre as possibilidades didáticas de sua atuação pedagógica. Além disso, coloca-se também como uma participante do grupo, compartilhando com eles e elas lembranças de sua infância. 
Erickson (1982), ao chamar a atenção para o componente de improviso presente em situações de interação em sala de aula, argumenta que as lições escolares podem ser definidas como "encontros educacionais", pois são situações em que professores e alunos seguem regras normativas, culturalmente aprendidas, mas também inovam juntos, dando novos sentidos a circunstâncias do momento. Nesse processo, os alunos são considerados participantes ativos e não apenas destinatários da ação do professor.

A mestra parece dar atenção especial à forma como as crianças se relacionam com a tarefa, sendo esse um elemento decisivo na maneira como conduz a aula. Ou seja, o trabalho desenvolvido por ela com seu grupo de alunos(as), revela que sua atuação está centrada nas crianças: nas suas necessidades de aprendizagem, no interesse e desempenho destes(as) durante a tarefa, nos resultados obtidos com o trabalho. Todo o encaminhamento do trabalho pedagógico obedece uma análise constante, por parte dela, dos indícios dados pelos(as) alunos(as) de como estão se relacionando com as atividades.

Essa preocupação se materializa em outras atitudes e instrumentos utilizados na condução do trabalho pedagógico. 0 primeiro instrumento que utiliza para envolver as crianças é a apresentação do roteiro de atividades previstas para o dia de aula (pauta). Às vezes, é apenas lido, mas na maior parte do tempo é escrito na lousa e ali permanece durante toda a aula. Várias vezes, a pauta serve de orientadora da sequência das tarefas: quando a professora alerta os(as) alunos(as) para que se apressem, pois há muito por fazer; ou quando um(a) aluno(a) interessado(a) em alguma atividade específica prevista na pauta apressa-se em cumprir as anteriores para poder acompanhar os(as) colegas na referida atividade (assistir a um vídeo, por exemplo).

Certificar-se de que todos os alunos e alunas tenham compreendido o que devem fazer é outro recurso que a professora utiliza para garantir o envolvimento das crianças. Para isso, ao encaminhar as atividades, apresenta apenas uma de cada vez, explica-a com clareza para a sala toda e, se necessário, explica novamente para as duplas nas carteiras ou para algum(a) aluno(a) individualmente. Em muitas situações, dá exemplos para que possam entender melhor o que está sendo solicitado. A análise da prática da professora articula-se com o resultado de outras pesquisas na área do ensino analisadas por Gauthier et al. (1998) as quais

[...] indicam que os professores que dão instruções claras, explícitas, redundantes (repetidas mais de uma vez) e compreendidas por todos os alunos levam-nos a se aplicarem mais às suas tarefas durante o trabalho individual. (p. 215)

Durante a realização das atividades, a professora está atenta ao desempenho do grupo, ao mesmo tempo que atende as duplas ou cada aluno(a) nas carteiras. Constantemente estimula-os(as) a não perderem tempo e assim que percebe a conclusão da atividade pela maior parte deles(as), acrescenta mais um exercício ou encaminha outra atividade. 0 oferecimento de tarefas extras para as crianças que concluem o exercício, tais como leitura de livros, revistas, fichas ou a realização de desenhos, contribui para mantê-los(as) ocupados(as) enquanto auxilia as crianças mais lentas.

\section{A dimensão criadora dos saberes no planejamento da ação pedagógica}

Na primeira cena, analisamos uma situação em que a inovação na condução da aula parece ter ocorrido no momento da atuação. Porém, o mais comum no trabalho dessa professora é que as atividades criadoras sejam fruto de um difícil processo de reflexão explicitado claramente por ela, seja em nossas conversas durante o período de observação, seja em seus relatórios sobre os projetos desenvolvidos.

Uma dessas situações pode ser conhecida por meio da Cena 02, apresentada a seguir, durante a qual se observa por parte da professora a busca de sintonia entre o interesse 
das crianças, o desempenho delas e a proposta de trabalho como um desafio constante para no planejamento de suas aulas. Nessa situação buscamos evidenciar o espaço de criação existente entre a proposta de uma atividade a ser desenvolvida pelos(as) alunos(as) e a forma como essa mesma atividade será conduzida em sala de aula. Mesmo que a tarefa a ser proposta tenha sido inspirada em manuais didáticos, ou em sugestões oriundas dos cursos de formação, a maneira como a professora concebe, organiza e desenvolve a atividade demanda uma criativa articulação de saberes, recursos e encaminhamentos que dependem de uma detalhada análise de variáveis do contexto, conforme nos revela o registro realizado pela professora.

Em outro momento do trabalho tínhamos como proposta fazer a leitura de uma música com rima e conversar com as crianças sobre a possibilidade de trocas de algumas palavras por outra. Li algumas músicas com rimas para que as crianças fizessem a escolha de uma para que pudéssemos fazer a troca e reescrever uma outra música.

Escolheram "A barata diz que tem"2. Cheguei a pensar que poderia não dar certo, que poderíamos não dar conta... Em casa, à noite, comecei a pensar nas possibilidades de encaminhamento para a atividade. Propus que listássemos coisas de uso escolar. Esta atividade tive que ir dirigindo e procurando caminhos para que as crianças participassem ativamente e déssemos conta do recado.

Encaminhei a seguinte proposta: 'Precisamos fazer uma lista para que possamos trocar algumas palavras da canção original e reescrever uma outra canção, de forma que rimem os versos para que possamos cantá-la. Pensei que poderemos listar nomes de materiais escolares, de coisas encontradas na sala de aula e também nomes de alguns alunos'.

Ouvi um Oba! Em coro. 'Bem, já que todos concordaram, eu vou fazer algumas perguntas e vou listando as respostas no quadro-de-giz. Depois vocês darão outras sugestões'.
Perguntas:

1- Tipo de roupa exigida para os alunos na escola? Uniforme.

2- Tipos de textos que usamos para fazer nossas leituras? Parlendas, lendas, fábulas, adivinhas etc.

3- Usamos para escrever? Canetinha, caneta, lápis, lapiseira, lápis de cor etc.

4- Nome dos alunos começados com as letras

$\mathrm{L}, \mathrm{V}, \mathrm{F}$. As letras que tinham mais que um aluno que iniciava com a mesma letra, decidimos no sorteio.

De início a atividade foi um pouco trabalhosa exigiu muita intervenção de minha parte, mas a partir da terceira estrofe as crianças fizeram as trocas, utilizando-se da lista, da letra original e das rimas, como uma atividade que já tivessem familiaridade.

Demonstraram alegria em cantar a canção e a todo momento se ouvia um ou outro cantarolando.

Cantiga construída:

\section{Os alunos diz que tem ${ }^{3}$}

Os alunos diz que tem

Uniforme de filó

É mentira dos alunos

Eles têm é guarda-pó.

$\mathrm{Ah}, \mathrm{Ah}, \mathrm{Ah}, \mathrm{Oh}, \mathrm{Oh}, \mathrm{Oh}$,

Eles têm é guarda-pó.

A Letícia diz que tem

Cinco livros de parlenda

É mentira da Letícia

Ela tem um só de lenda.

$\mathrm{Ah}, \mathrm{Ah}, \mathrm{Ah}, \mathrm{Oh}, \mathrm{Oh}, \mathrm{Oh}$,

Ela tem um só de lenda.

A Valéria diz que tem

Um anel de formatura

É mentira da Valéria

0 anel é lata pura

$\mathrm{Ah}, \mathrm{Ah}, \mathrm{Ah}, \mathrm{Oh}, \mathrm{Oh}, \mathrm{Oh}$,

0 anel é lata pura.

2. Canção de domínio popular.

3. Embora a concordância esteja gramaticalmente incorreta, acreditamos que a professora tenha conservado esta forma para aproximá-la da canção que originou a produção das crianças. 
O Frank diz que tem

Lapiseira de grã-fıno

É mentira do Frank

Ele tem é lápis fino

$\mathrm{Ah}, \mathrm{Ah}, \mathrm{Ah}, \mathrm{Oh}, \mathrm{Oh}, \mathrm{Oh}$,

Ele tem é lápis fino.

Os alunos do CBA

Diz que gostam de brincar

É mentira dos alunos

Eles gostam é de estudar

$\mathrm{Ah}, \mathrm{Ah}, \mathrm{Ah}, \mathrm{Oh}, \mathrm{Oh}, \mathrm{Oh}$,

Eles gostam é de estudar. (Relatório do Proje-

to Cantigas de Roda, 2003, p. 7-10)

Essa Cena foi protagonizada no $1^{\circ}$ semestre do ano letivo, quando a professora trabalhava novamente com uma primeira etapa do Ciclo Básico, e nela se pode identificar a preocupação da professora com o encaminhamento da atividade de forma que as crianças pudessem participar de maneira organizada e produtiva. É importante ressaltar que no ano anterior, com a turma de $2^{\text {a }}$ etapa do Ciclo, ela havia encaminhado uma atividade semelhante em que as crianças fizeram mudanças na rima de poesias, porém, naquela ocasião a produção foi individual e, portanto, não dirigida ${ }^{4}$.

Um dos aspectos importantes que emergem do fragmento do relatório escrito pela professora está relacionado ao esforço demandado por ela para planejar a atividade que realizou com seu grupo de alunos. 0 texto da mestra revela que 0 ato criador não comparece apenas na forma de encaminhamento da atividade, mas também em sua maneira de refletir sobre o trabalho com as crianças. Ao pensar nas dificuldades que as crianças enfrentarão para a realização da proposta, a professora se faz perguntas que permitem encontrar alternativas para desenvolvê-la. Suas indagações demonstram que ela deposita nas crianças a necessidade e a possibilidade de aprender e por isso suas buscas se dão na direção de saber como deverá proceder para dar as pistas necessárias para que a tarefa possa ser compreendida pelas crianças e, portanto, realizável.

0 esforço de antecipação das circunstâncias da aula aponta para a importância do planejamen- to, conforme explica a própria professora em uma das entrevistas realizadas durante a pesquisa:

Hoje eu sei que não adianta eu ir com qualquer atividade pra minha sala... Então eu tenho que estar pensando: o que eu vou encaminhar? De que maneira eu vou encaminhar aquilo ali. Teve um artigo que eu fiz, não sei se foi um artigo, ou projeto, não sei o que foi. Menina! Eu cheguei em casa saía fumacinha assim! Como eu ia encaminhar aquela... Ah! Foi o projeto de cantigas de roda, lá do PROFA [Programa de Formação de Professores Alfabetizadores]. Como eu ia encaminhar aquela atividade [...] para a reescrita daquela música. Como? Eu queria usar o nome das crianças, trocar pelo nome da barata. E como eu ia jogar essas perguntas pra eles, pra tirar deles, pra que não ficasse uma coisa pra eu construir. Fui dormir uma e meia da manhã, quando eu consegui organizar. (Entrevista, jan. 2004)

No registro da professora pode-se entrever que as crianças, além de se envolverem em uma atividade lúdica com as palavras, em que escrever tornou-se instrumento de criação de outra canção, aprenderam um procedimento de produção. Isto é, aprenderam a lidar com vários elementos para a escrita de um novo texto:

[...] a partir da terceira estrofe as crianças fizeram as trocas, utilizando-se da lista, da letra original e das rimas como uma atividade [com] que já tivessem familiaridade. (Entrevista, jan. 2004)

A preocupação da professora em garantir a participação, o envolvimento e o prazer dos alunos durante a realização da atividade, aspectos

4. Naquela ocasião pudemos observar a recriação da poesia "Cadê?". Poesia original: "Nossa! Que escuro!/ Cadê a luz?/ Dedo apagou./ Cadê o dedo?/ Entrou no nariz./ Cadê o nariz?/ Dando Espirro./ Cadê o espirro?/ Ficou no lenço./ Cadê o lenço?/ Dentro do bolso./ Cadê o bolso?/ Foi com a calça./ Cadê a calça?/ No guarda-roupa./ Cadê o guarda-roupa?/ Fechado a chave./ Cadê a chave?/ Homem levou./ Cadê o homem?/ Está dormindo/ de luz apagada./ Nossa! Que escuro." (Paes, 1999).

Poesia escrita por Roberto: "Cadê?/ Cadê o palhaço?/ Está no circo./ Cadê o circo?/ Está na cidade./ Cadê a cidade?/ Está no mapa./ Cadê o mapa?/ Está perdido!/ Vamos procurar?". 
que fez questão de registrar em seu relatório, estiveram presentes em todos os momentos da pesquisa. Sua atitude em relação às crianças sempre foi de convencimento com base em argumentos ou estímulos, nunca por meio de imposição ou punição. Além disso, sua atenção constante aos interesses dos alunos permite que ela modifique a atividade no momento em que esta não atendeu as expectativas ou não desencadeou o desempenho esperado nas crianças. Com esse tipo de procedimentos, dificilmente a professora enfrenta problemas com as crianças em relação à realização das atividades, pois, como ela mesma esclarece:

Eles têm dificuldade, alguns realmente têm. Mas que eu proponho as atividades e eles não querem fazer, nunca tive dificuldade. Eles fazem até demais, se deixar. É lógico, tem algumas atividades que a gente propõe que eles não gostam e eles falam mesmo. Mas eu deixo eles trocarem, eu troco, depois a gente questiona porque eles não gostaram... Isso nunca me incomodou. As crianças, deixar de fazer... eu tenho que perceber que eles estão aprendendo. Se eu vejo que eles estão aprendendo, não me incomoda. (Entrevista, jan. 2004)

As palavras da professora traduzem o foco de sua atenção: a aprendizagem das crianças. As atividades são instrumentos que utiliza para atingir seus objetivos. 0 fato de uma criança deixar de fazer a tarefa em determinado momento, mas fazê-la depois, ou ao invés de escrever o texto proposto escolher um outro não significa um problema para a professora. Seriam necessárias, no entanto, maiores investigações no sentido de verificar se essas alterações não acabam por significar uma simplifıcação da atividade, impedindo um maior avanço das crianças.

\section{Considerações finais}

A dimensão criadora dos saberes docentes, evidenciada na análise da prática pedagógica da professora, a partir do conceito de atividade criadora conforme proposto por
Vigotsky (2003), permite compreender que a prática docente no cotidiano não se caracteriza apenas como reprodução de modelos ou propostas utilizadas por outros profissionais. Ao contrário, em uma sala de aula, quando se reúnem uma professora e uma turma de alunos, há sempre certa originalidade nesse encontro, o que demanda dos docentes a criação de formas específicas de intervenção para aquele grupo nas condições do contexto.

Conforme explicitado no início deste artigo, para Vigotsky (2003), a atividade criadora não é fruto de inspiração momentânea ou capacidade herdada, mas é produto da combinação ou modificação de elementos que permitem a criação de algo novo sendo, portanto, influenciada pela riqueza de experiências, informações e conhecimentos apropriados pelos sujeitos. Nesse sentido, os saberes docentes apresentam uma dimensão criadora se os professores, de posse desse contexto, puderem articular, de forma inovadora, os conhecimentos e as experiências apropriadas ao longo de sua história de formação e atuação e recombiná-los de outra maneira em função das necessidades e possibilidades do cotidiano.

Acompanhar o trabalho da professora durante o período da pesquisa permitiu-nos compreender que há inúmeras possibilidades de condução do trabalho pedagógico e as razões que motivam as escolhas dos professores e das professoras estão fundamentadas em saberes construídos ao longo de suas experiências de formação e atuação. Por isso, as práticas pedagógicas precisam ser conhecidas e estudadas para que possamos compreendê-las mais do que avaliá-las. A partir desse conhecimento será possível construir propostas de intervenção tanto na organização das escolas quanto nos programas de formação inicial e continuada que estimulem a autonomia docente para construir formas próprias de atuação que sejam fruto da atividade criadora dos(as) professores(as) e não resultado da expropriação dos saberes docentes em favor de modelos construídos em contextos alheios à cultura escolar onde atuam. 
Esses dados nos alertam, ainda, para a importância de proporcionar aos professores e professoras em formação oportunidades para que exercitem a capacidade de articular conhecimentos teóricos, condições objetivas dadas em espaços escolares e necessidades específicas de grupos de alunos, de modo criativo e inovador. É ne- cessário que esses professores e essas professoras proponham formas de intervenção que possam ser experimentadas, analisadas e socializadas coletivamente, de maneira que os professores e professoras apreendam a amplitude do desafio que representa a docência e não a entendam como a aplicação de um conjunto de técnicas ou modelos pré-existentes.

\section{Referências bibliográficas}

BORGES, C. M. F. 0 professor da educação básica de $\mathbf{5}^{\mathbf{a}}$ a $\mathbf{8}^{\mathbf{a}}$ série e seus saberes profissionais. 2002. Tese (Doutorado)Pontifícia Universidade Católica do Rio de Janeiro, Rio de Janeiro. 2002.

. Saberes docentes: diferentes tipologias e classificações de um campo de pesquisa. Educação e Sociedade, v. 22, n. 74, p. 59-76, abr. 2001.

DUARTE, N. Vigotski e o "aprender a aprender": crítica às apropriações neoliberais e pós-modernas da teoria vigotskiana. Campinas: Autores Associados, 2000.

ERICKSON, F. Classroom discourse as improvisation: relationships between academic task structure and social participation structure in lessons. In: WILKINSON, L. C. (Ed.). Communicating in the classroom. New York: Academic Press, 1982. p. 153-181.

GAUTHIER, C. et al. Por uma teoria da pedagogia: pesquisas contemporâneas sobre o saber docente. ljui: Editora Unijui, 1998.

HELLER, A. 0 cotidiano e a história. 4. ed. Rio de Janeiro: Paz e Terra, 1989.

Sociología de la vida cotidiana. 2. ed. Barcelona: Península, 1987.

MERCADO, R. Los saberes docentes en el trabajo cotidiano de los maestros. Infancia e aprendizaje, México, n. 55, p. 59-72, 1991.

. Los saberes docentes como construcción social: la enseñanza centrada en los niños. México: Fondo de Cultura Económica, 2002.

PAES, I. P. Lê com crê. 9. ed. São Paulo: Ática, 1999.

PIMENTA, S. G. Formação de professores: identidade e saberes da docência In: docente. 3. ed. São Paulo: Cortez, 2002. p. 15-34. (Org.). Saberes pedagógicos e atividade

ROCKWELL, E. Desde la perspectiva del trabajo docente. México: DOC-DIE, 1990.

; MERCADO, R. La práctica docente y la formación de maestros. La escuela, lugar del trabajo docente. México: Centro de Investigación y de Estudios Avanzados del IPN, 1986. p. 63-75.

TALAVERA, M. L. Como se inician los maestros en su profesión. 2. ed. La Paz: CEBIAE, 1994.

TARDIF, M. Saberes docentes e formação profissional. 2. ed. Petrópolis: Vozes, 2002.

VIGOTSKY, L. S. La imaginación y el arte en la infancia. Madrid: Akal, 2003. 
ZORZAL, M. F.; BASSO, I. S. Por uma ontologia da criatividade: uma abordagem histórico-cultural. In: 25ª Reunião anual da Associação Nacional de Pós-Graduação e Pesquisa em Educação, 2002, Caxambu. Anais... 1 CD-ROM.

Recebido em 09.11 .09

Aprovado em 04.05.10

Marli Lúcia Tonatto Zibetti é doutora em Psicologia Escolar e do Desenvolvimento Humano, Professora do Departamento de Educação da Universidade Federal de Rondônia (UNIR) - Campus de Rolim de Moura. Coordenadora do Grupo de Estudos e Pesquisas em Psicologia e Educação na Amazônia (GEPPEA).

Marilene Proença Rebello de Souza é doutora em Psicologia Escolar e do Desenvolvimento Humano, Professora do Departamento de Psicologia da Aprendizagem, do Desenvolvimento e da Personalidade do Instituto de Psicologia da Universidade de São Paulo (USP). Coordenadora do Grupo de Pesquisa Psicologia Escolar e Educacional: processos de escolarização e atividade profissional em uma perspectiva crítica. E-mail: mprdsouz@usp.br. 